\title{
Work in Progress: A Path to Graduation: Helping First-Year Low Income, Rural STEM Students Succeed
}

Dr. Carol S. Gattis, University of Arkansas

Dr. Carol Gattis is the Associate Dean Emeritus of the Honors College and an adjunct Associate Professor of Industrial Engineering at the University of Arkansas. Her academic research focuses on STEM education, developing programs for the recruitment, retention and graduation of a diverse population of students. Carol also serves as a consultant specializing in new program development and grants. She earned her bachelor's, master's and Ph.D. degrees in Electrical Engineering from the U of A and has served on the industrial engineering faculty since 1991.

\section{Xochitl Delgado Solorzano, University of Arkansas}

Xochitl Delgado Solorzano is the director of the Honors College Path Program at the University of Arkansas. In this capacity she oversees all aspects of the Path Program, including recruitment and student success, grant requirements, and fundraising.

\section{Don Nix, University of Arkansas}

Don Nix, MSW, directs the Accelerate Student Achievement Program and the 360 Advising Program at the University of Arkansas. Don's work, part of the university's broader Student Success initiatives, centers on providing proactive academic and social support to first generation college students, low-income students, and students with demonstrated need for academic support during the transition from high school to college.

\section{Jennie S. Popp Ph.D., University of Arkansas}

Jennie Popp, Ph.D. is a Professor of Agricultural Economics and the Associate Dean of the Honors College at University of Arkansas. As Associate Dean, Dr. Popp contributes to student success initiatives through the management of Honors College study abroad and research grant programs, the facilitation of the development of service learning and other new courses, promotion of undergraduate research activities and in contributions to the PTG and Honors College Path programs. Her research has focused on identification and implementation of sustainable agricultural best management practices. She has been the lead or co-principle investigator on over \$20 million in federally competitive grants to support her research.

\section{Ms. Michele Cleary, Cleary Scientific Intelligence, LLC}

Ms. Michele Cleary is the founder and owner of Cleary Scientific Intelligence, LLC., working with academic, technology, and life science clients. She specializes in synthesizing scientific literature, policy analyses, and research data into accessible and persuasive proposals, reports, white papers, and marketing materials. Ms. Cleary earned her BA in Biology from Macalester College and did her doctoral work in Health Services Research from the University of Minnesota.

\section{Dr. Wenjuo Lo, University of Arkansas}

Dr. Wen-Juo Lo is an Associate Professor in the Educational Statistics and Research Methodology (ESRM) program at the University of Arkansas. His research interests involve methodological issues related to analyses with a focus on psychometric methods. The recent research agenda concentrates statistical methods for the detection of bias in psychological measurement, especially measurement invariance on latent factor models. In addition, he also conducts research to develop effective latent variable model and instrument that reflects the factors of college students' retention.

\section{Dr. Bryan Hill, University of Arkansas}


Bryan Hill earned a B.S. and M.S. in Industrial Engineering and a Ph.D. in Public Policy from the University of Arkansas. Currently, Bryan is the Associate Dean for Student Success at the University of Arkansas College of Engineering. He is also director of UAteach, a secondary math, science and computer science teacher education program. Bryan has more than 15 years of experience in engineering student recruitment, retention, diversity initiatives, and K-12 outreach programs. Bryan is PI on STEM educational and outreach grants totaling $\$ 6.6 \mathrm{~m}$.

\section{Dr. Paul D. Adams, University of Arkansas}




\section{Work in Progress: A Path to Graduation: Helping First-Year Low Income, Rural STEM Students Succeed}

\section{Introduction}

While the STEM-based economy has been an enormous economic boon for some parts of the United States, other states, especially those more rural and economically beleaguered states, are falling further behind economically due in part to their inability to meet engineering labor demands. Ranking $49^{\text {th }}$ in college attendance and $45^{\text {th }}$ in per capita Bachelor of Science engineering and science degrees [1], Arkansas is an example of one such state struggling to meet its STEM labor needs. However, the state could close this labor gap in part by recruiting previously overlooked students - low-income and rural students. The University of Arkansas' Path to Graduation (PTG) aims to increase the number of low-income students, especially those from rural regions, who graduate with an engineering degree. Previous student recruitment and retention efforts have largely ignored the unique challenges faced by low-income students from rural areas. These students often struggle with academic persistence in college due to insufficient funds, poor academic preparation by their small, financially-struggling schools, and little social support given the lack of college-going culture in their communities. PTG adapts proven student retention and graduation initiatives to better address the financial, academic, and social barriers to success so that these students can thrive, succeed, and excel in their studies. The intent of the program is to increase both the size and the diversity of Arkansas' STEM labor pool, while creating best practices for recruiting and retaining low-income students, especially those from rural areas. These practices can then be implemented in other remote, poor regions across the country, developing pipelines of talent, improving these regions' economic well-being, and bringing much needed diversity to STEM fields.

Through academic, financial, and social initiatives, PTG will help up to 36 students thrive and excel in their STEM degree programs at the University of Arkansas. Students will be recruited largely from rural, impoverished regions of Arkansas where large populations of underrepresented minority and first-generation students are prevalent but opportunities for a STEM education are not. Two cohorts of up to 18 STEM students per year will receive annually renewable scholarships of up to $\$ 4,500$, or up to $\$ 5,500$ if they join the Honors College. These students will participate in PTG's evidence-based retention and graduation initiatives, including: an in-residence summer bridge program; a Living-Learning Community (shared housing); Academic Success Advising; faculty and peer mentoring; and on-campus or industry-based research opportunities. PTG will help identify and describe the barriers deterring low-income students, especially low-income students from rural backgrounds, from achieving a STEM degree. PTG will develop and implement retention programs for low-income, rural STEM students and will contribute significantly to the STEM education literature by developing and evaluating much needed initiatives for under-served, low-income, rural populations that frequently struggle with academic persistence.

\section{Generation of Knowledge}

Given the dearth of STEM professionals in Arkansas and its high poverty rate, low college attendance, and limited opportunities due to the rural nature of the state, the University of Arkansas 
is particularly interested in helping more low-income, rural students obtain a STEM degree. To this end, the University of Arkansas is particularly interested in retention and graduation interventions focused on low-income and/or rural STEM students.

Expanding STEM educational opportunities to the rural poor is fraught with challenges quite different from those impacting urban poor. While both groups of students must tackle financial, academic, and social barriers to achieving a STEM degree, geographic isolation impacts the rural poor in particular ways that can affect their academic careers. PTG seeks to better understand these barriers and to tailor academic and social support initiatives so that these students may thrive in college. This section summarizes what is known about rural, low-income STEM students, how existing retention initiatives may be adapted to support these students, and how PTG may contribute to this knowledge base.

Rural Arkansas continues to struggle economically, which has greatly limited K-12 academic offerings for its students. Urban migration has meant an eroding tax base, leading to financially struggling school systems [2]. These schools struggle to meet the mandated curriculum; few rural schools can afford to offer their students extensive Advanced Placement (AP) courses [3]-[5]. Not only does this leave rural students less academically-prepared than their urban peers, these rural students' GPAs cannot benefit from the inflating impact of taking AP courses, meaning that they are less competitive for academic scholarships than students from urban areas where AP offerings are more plentiful [3]-[5]. Rural students also lack access to test preparation services, which can result in lower ACT/SAT scores, further limiting their scholarship opportunities.

Students from rural areas also lack access to non-school based academic enrichment opportunities in their communities, such as summer day camps. Limited exposure to academic enrichment erodes student confidence, especially in their ability to succeed in STEM programs, where rural students commonly hold the belief that they lack the academic preparation to succeed [6], [7]. Academic confidence, also known as academic self-efficacy, has been shown to be strongly associated with academic persistence and achievement [8]-[13], especially in STEM [14].

Finally, rural students, especially those from low-income families, face social barriers stemming not only from geographic isolation, but also from the very low prevalence of academic role models. Very few rural Arkansans have college degrees (14\% versus 25\% in urban Arkansas), far lower than the national average of $31 \%$ [2]. Rural students may have little family support for their college endeavors. In addition, these rural regions have a far lower percentage of STEM professionals compared with urban area, meaning students may know very little about STEM careers and the opportunities these jobs may afford. With little family or community support and understanding of a student's college pursuit, coupled with the significant geographic distance college requires, the social barriers facing these rural students may eclipse the financial and academic barriers challenging them.

As discussed below, the STEM education literature, especially in engineering, demonstrates the enormous value of student recruitment, retention, and graduation initiatives that remove financial, 
academic, and social barriers to student persistence. But few of these initiatives have examined their effectiveness in helping rural, low-income students.

As mentioned above, rural students may be less likely to receive academic scholarships due to their limited access to AP courses, standardized test preparation courses, and non-school-based enrichment offerings. Financial need is another primary factor impacting persistence [15], [16]. Financial need impacts STEM students especially hard, as low-income families have been found to be far more averse to take out large student loans; often low-income students choose to pursue a two-year degree or not attend college at all [17]-[19]. While many students may cover part of their school costs with employment, this path is especially risky for STEM students. STEM students who work are significantly less likely to complete their degree [22], with non-completers more likely to be working 15 hours or more per week [21]. For low-income students, scholarships and grants are the most effective type of financial aid to help them attain their degrees [22], especially for underrepresented minority students [19], [23]-[26]. However, little has been published on the impact of scholarship aid on academic achievements of rural STEM students of poverty. PTG will examine whether a standard scholarship will positively impact student achievement.

Many initiatives have been developed to help support students academically, including various summer bridge programs, tutoring, and faculty-guided research opportunities. Academic tutoring has been shown to significantly increase students' chances of success [27]. Bridge programs help entering students who may not be fully prepared academically by allowing them to take courses prior to their first college semester so that they can join the cohort in the fall with strengthened skills and increased academic self-efficacy [38]. These summer bridge programs have been demonstrated as effective retention mechanisms, especially for African-American and Latina(o) students attending predominantly white institutions [29], [30]. Finally, studies have shown that research participation helps students sustain their interest in STEM and in their studies [31]-[41]. However, their use with rural students from low-income families remains unexamined.

Isolation is a major factor fueling many students' decision to leave their degree programs. Support during the transition to college is a significant determinant as to whether a student will persist with their degree [42]. But feelings of isolation often continue long past that initial semester. A student's belief that they 'do not belong' has been shown to significantly reduce student persistence in engineering, especially among underrepresented minority students [43]-[47]. Faculty and peer mentoring can greatly improve student retention. Faculty mentoring helps reduce student feelings of isolation, while also enhancing students' professional development [48], [49] and persistence [50]-[52]. Peer mentoring has been shown to significantly increase STEM students' desire to continue their degree programs, an effect especially pronounced in minority students [53]. At the University of Arkansas, engineering students who met with their peer mentor at least eight times during the year were significantly more likely to persist through their undergraduate program [54]. Finally, students living within an academic community (e.g. Living Learning Community) have been shown to build stronger academic and social connections, leading to improved academic achievement and significantly longer retention [55], [56]. 
The University of Arkansas is very concerned about refining retention and graduation interventions to meet the needs of low-income STEM students from rural areas. Building a strong, successful STEM program requires an understanding of the barriers students face while pursuing their degree, especially in an EPSCOR state like Arkansas. With pervasive poverty statewide, a rapidly growing immigrant population, few academic role models due to the state's extremely low rate of college attendance, and rapidly rising costs, college is viewed as an unattainable goal for a large portion of Arkansas high school students. Therefore, recruitment and retention strategies need to be especially sensitive to the issues so prevalent in Arkansas, as well as EPSCOR states, in general. PTG will provide valuable insight into how current retention strategies may best accommodate the needs of rural students from low income families interested in studying STEM.

\section{Program Overview and Components}

The PTG program aims to recruit, retain, and graduate rural students with financial need who have entering academic credentials that are not typically high enough to qualify for university scholarships, but who show strong academic promise. PTG provides support and opportunities tailored to engineering and science students from rural and underserved areas to help these students perform to their full potential. Through targeted recruitment in the often-overlooked rural communities and by identifying solid students without the highest standardized test scores, a pool of students can be tapped that otherwise would not likely pursue an engineering or STEM degree. The program also provides students with opportunities to excel academically by integrating honors programming opportunities and resources.

\section{Recruitment and Selection of Candidates}

The NSF award notification was received in December 2017 with the grant beginning in January 2018, thus the recruitment cycle, which normally begins the preceding August was shortened by five months. Nevertheless, although a quality pool of candidates was identified. The PTG team worked with the Office of Admissions, which provided a comprehensive list of University of Arkansas applicants who met the PTG recruitment criteria (intended major in an NSF S-STEM approved STEM field (engineering and physical sciences, but not premed), high school GPA of 3.5+, ACT 23-27 (or SAT of 1290-1550), and high school address with rural zip code). Rural zip codes were identified using the Center for Medicare and Medicaid Services (CMS) Rural Zip Code list [57]. PTG eligible students were also identified through conversations during recruitment events, and through other University programs and offices that work with students in rural areas. A PTG website was created to promote the program and the NSF S-STEM scholarship [58], while further information was shared through initial and follow up correspondence (e-mails, phone calls, mailings). An Office of Admissions staff member located in Eastern Arkansas and dedicated to recruiting underrepresented students assisted in recruiting potential PTG students by identifying potential students and by helping those students complete the FAFSA (Free Application for Federal Student Aid).

All eligible students were invited to apply for the PTG program. The application process consisted of applying to the university, completing a short PTG application, and submitting the FAFSA to determine financial need eligibility. PTG students must be eligible for the Pell Grant or Subsidized 
Stafford Loans. Finally, a postcard was sent to students meeting the criteria to ensure their parents would see the scholarship information.

For the second year of recruitment, the recruitment and application process was changed due to the longer recruitment cycle. PTG recruitment efforts were expanded to include additional rural communities, thus widening the engineering and PTG applicant pool. The PTG website has also been expanded to include a student testimonial and video, sharing a PTG student's experience. A student blog section highlights current PTG students for the future scholars. PTG candidates are also now required to apply for other University scholarships to help further remove financial challenges. Even though most of these scholarships are relatively small, each student's scholarship application provides information critical to the selection of PTG finalists. Questions from this year's application include: "What career are you interested in pursuing? What are you hoping to experience during your undergraduate education that will best prepare you for that path?, Why is it important for you, as a candidate to the PTG Program, to attend the University of Arkansas? What will you personally contribute to the campus community?"

From the qualified candidate pool, 18 were selected as PTG finalists. These finalists were invited to a PTG interview weekend hosted and funded by the Honors College and the College of Engineering. The candidates were hosted by HC Path students and housed in their Honors residence hall rooms. Candidates' parents/guardians were provided hotel rooms.

Much of the PTG program was inspired by the HC Path program. HC Path students have a similar entry profile as the PTG students, and HC Path students have access to HC housing, programming, activities, advising, and mentoring. However, the HC Path program did not offer some of the PTG components, such as the bridge program, faculty mentoring and research clusters, and scholarships. Also, while the HC Path program is available to students from all majors, PTG is limited to engineering and science majors. Since the NSF PTG award, the HC Path incorporated these additional PTG components.

Throughout the interview weekend, the candidates interacted with university administrators, faculty, and current HC Path students. On Friday evening, the candidates and their families participated in a two-hour welcome dinner event. The event's core message to these students was to achieve academic excellence through rigorous coursework and cutting-edge research opportunities; to embrace diversity and inclusion, and proudly represent the underrepresented; and to engage socially, building lifelong friendships. After the dinner, families returned to their hotels and candidates were escorted by their hosts to the residence hall. The next morning, each finalist had a 15-minute interview with a panel consisting of a PTG team member, an HC Path student, and an engineer from a local company. Activities continued throughout the morning, engaging candidates, and helping facilitate relationships between candidates and with HC Path students. Once interviews concluded, candidates were reunited with their families at a local restaurant for a closing meal.

After the interview weekend, 15 students were selected as PTG scholars, of whom 14 accepted the invitation. This inaugural PTG cohort includes 11 engineering students, 3 non-engineering STEM students (one each in chemistry, physics and biology), 5 women, and 7 students from underrepresented minority populations. One student from the 2018 cohort dropped out after the 
fall 2018 semester, citing personal reasons. For the 2019 cohort, up to 22 students are expected to join the PTG program.

\section{Addressing Financial Barriers to Success}

Scholarships have been shown to increase the likelihood that students with severe financial need will persist in college. All PTG students have a high level of financial need, demonstrated by their being Pell Grant and/or Subsidized Stafford Loan eligible. PTG scholarships are critical to removing remaining financial barriers that may threaten persistence. PTG scholarships total up to $\$ 4,500$ for students who have not joined the HC (including all PTG freshmen) and up to $\$ 5,500$ for students if they join the HC. Students financial aid packages comprising all grants and scholarships are capped at the cost of attendance. Scholarships are renewable for up to 4 years provided the student: remains in an NSF-listed STEM major, keeps at least a 3.0 GPA, and participates actively in the program. Students whose GPA falls below the 3.0 threshold can request a semester of probationary status while they work to improve their GPA to above the minimum threshold. Students who join the HC will also have access to further financial assistance, such as study abroad grants and undergraduate research grants.

\section{Addressing Academic Barriers to Success}

\section{Summer Bridge Program}

The 5-week summer bridge program supports participants in completing an early college experience prior to their traditional fall semester start at the university. The primary objectives of the bridge experience are to create an environment in which participants gain experience with the rigor and expectations of college-level coursework and foster a sense of connectedness with the university community. The summer bridge program is funded in full through the NSF PTG scholarships.

In summer 2018, during the university's second five-week semester, PTG participants lived on campus and attended classes along with participants of two already established bridge programs at the university. This combined group of 150 bridge program students placed PTG participants within a network of similarly situated peers, as well as mentors (peer and professional), with whom to navigate the summer semester.

PTG students who intended to major in engineering, but who did not meet the ACT/SAT math requirement to enter Calculus I in the fall semester, attended the Engineering Math Acceleration Program (EMAP). EMAP is a 5-credit hour course that combines college Algebra, Trigonometry and Pre-Calculus within an engineering context. PTG students, along with other EMAP students, participated in coursework, study hours, and tutoring. The two PTG students who were Calculus I ready took 6 credit hours that count toward their engineering degree.

All PTG students participated in a one-credit hour research course developed by a University of Arkansas engineering professor, Dr. Kevin Hall. Informally dubbed 'research lite,' the aim of this course was to demystify the research process. Pre-course surveys tested students on their understanding of what doing research meant and the role of ethics in research. It also asked 
students about their own research experiences (if any) and their perceptions about engaging in research in the future and the value of doing research at all.

Meeting each Wednesday afternoon for 3 hours, Dr. Hall walked the students through the purpose of research, the scientific method, a description of and the importance of ethical conduct, and communication of results. Dr. Hall adopted some of the materials presented in the book, Teach Students How to Learn [59]. Because the course was taught during a shorter summer session, time was insufficient for students to conduct a full research project of their own. Instead, students worked to develop a research proposal. They chose a topic, conducted a literature review around the importance of the work and any previous related work published, proposed methods to conduct the research, and listed expected results. This research proposal was presented as both a course research paper submitted in hard copy and as a PowerPoint presentation. Students presented to their class peers, while engineering faulty members were invited to the presentations to provide a critique of the students' ideas.

At the end of the course, students were surveyed again regarding all of the questions included in the pre-survey, as well as their overall satisfaction with the class. While no formal statistical analysis was conducted, a comparison of pre- and post-course results suggested the following: 1) some students improved their understanding of what research was and the importance of ethical conduct in research; 2) nearly all students improved their understanding of the value of conducting research that follows accepted scientific mentors; 3) some students who were hesitant about engaging in research before the course began stated they felt more confident in their ability to engage in undergraduate research.

\section{Faculty Mentoring}

Students were grouped together in clusters surrounding a research topic of common interest led by a volunteer faculty member. This faculty member would invite students to seminars, research team meetings, lab tours and other events that may be of interest to the students and help instill an interest in research. Five faculty-led clusters met twice each month. It was anticipated that this faculty-led interaction, by being included in research seminars within their academic departments and in tours of research labs, would help demystify the research process. This has proven to be more difficult in practice than in theory, as first-year student schedules rarely allow for these types of group meetings. This part of the program is currently being evaluated for re-envisioning for year-two freshmen and to determine the course of action for sophomore PTG students. The idea was to group students in these research clusters their freshman year, then hopefully having them join faculty-led undergraduate research teams, where they would then gravitate to those teams instead of the PTG research clusters. More study needs to be done by the PTG team in this area. It is hoped that the majority of PTG students will engage in undergraduate research with faculty.

The faculty who elect to lead PTG research clusters attend mentor training sessions (two in fall, one in spring) led by the Vice Provost for Diversity and Inclusion, and PTG co-PI, Dr. Yvette Murphy-Erby. The first two training sessions focus on best practices for engaging with students, understanding and recognizing their own inherent biases, as well as learning how to meet students where they are by sharing a research experience rather than imposing it upon a student. The upcoming third mentor training will expose faculty members to skills that will enhance their 
mentoring efforts, such as empathic listening, inspiring, motivating and goal setting, using effective communication strategies to provide constructive, authentic and supportive feedback and encouragement.

\section{Addressing Co-curricular Barriers to Success}

\section{Summer Bridge Program Co-Curricular Activities}

Bridge programming supports participants' in-class experiences while providing opportunities for personal and social growth. PTG participants were organized into small groups of 5 to 8 students led by live-in residential peer mentors. These peer mentors are rising sophomores, juniors, and seniors, most of whom have previously participated in a similar summer bridge program and who share common academic interests and life experiences with PTG participants.

Peer mentoring activities include the completion of weekly one-on-one and small group meetings of mentors and their assigned participants. Mentors follow weekly discussion guidelines to encourage participants' learning and reflection; topics include syllabus review, study planning, goal setting, time management, and networking on campus, among other topics.

In addition to formal peer mentoring activities, the bridge program environment provides frequent opportunities for participants to create informal connections with one another and other peer mentors. Participants are encouraged to form study groups for their commonly taken summer classes. Mentors help create clubs, interest groups, and social activities to encourage student and mentor interaction. The program also includes a number of large group social activities, including museum outings, cultural events, skating, bowling, and other area recreational activities, which build social bonds between bridge program participants outside of the classroom and residence hall environments.

Each week, PTG students, along with students from other bridge programs, met for a campus speaker series. Guest speakers from various campus offices presented on topics ranging from campus clubs and organizations, student government, campus life, and financial aid, to communication skills and goal setting.

Peer mentoring meetings, social activities, and group outings and meetings all serve to build a sense of community among PTG participants and participants in the other summer bridge programs, facilitating an environment in which students were encouraged to work together to create new social connections, try new approaches to learning, and become comfortable navigating their new surroundings.

\section{PTG Monthly Meetings}

PTG students are required to attend three monthly meetings each semester during which PTG program staff or an on-campus content expert present on topics critical for PTG student success at the University of Arkansas. (Table 1 summarizes topics covered during these meetings). First-year students focus on how to manage academic and social expectations of college, but also help these students plan out their academic goals and identify steps needed to reach these goals. Monthly 
meetings provide students opportunities to engage with campus-wide initiatives. Ideally, the meetings should also be an opportunity for PTG students to meet with other first and second-year HC Path scholars, to build community and share advice on navigating their university experience. However, because of the number of topics covered, there was little time for students to connect. In the future, PTG staff will work towards balancing the types of interactions between students and proving more opportunities to build community between cohorts.

Table 1. Topics covered during first-year PTG student monthly meetings

\begin{tabular}{|l|l|}
\hline 2018-2019 & Topic \\
\hline September & $\begin{array}{l}\text { Negotiating your college experience } \\
\text { Diversity and Inclusion training }\end{array}$ \\
\hline October & $\begin{array}{l}\text { How to be a mentee } \\
\text { How to interact with faculty } \\
\text { Long-term planning and academic mapping }\end{array}$ \\
\hline November & $\begin{array}{l}\text { Service learning } \\
\text { One Book, One Community Discussion }\end{array}$ \\
\hline February & $\begin{array}{l}\text { Resume/Interviews and Co-Ops/Internships } \\
\text { Study Abroad }\end{array}$ \\
\hline March & $\begin{array}{l}\text { Research } \\
\text { Scientific manuscripts/conference presentations }\end{array}$ \\
\hline April & $\begin{array}{l}\text { Graduate and professional school } \\
\text { Nationally competitive awards }\end{array}$ \\
\hline
\end{tabular}

\section{Professional Mentoring}

PTG students have access to both professional and peer mentoring from staff and from HC Path scholars, who are further along in their degree programs. PTG staff maintain an open-door policy with program participants in an effort to encourage open communication. PTG students are required to meet with PTG staff one-on-one for a mid-semester review to review the student's academic progress and develop a plan for continued/improved success. The mid-semester review is also an opportunity to discuss students' campus engagement and future plans.

\section{Peer Mentoring}

Many peer mentoring opportunities exist for PTG scholars. Relationships with peer mentors often begin during the bridge program and continue, usually meeting monthly, into the first-year. PTG students may consult with HC Path peer mentors throughout their time at the university. Engineering PTG students are paired with peer mentors through the First-Year Engineering Program, meeting with them monthly to discuss their adjustment/progress in engineering courses. Although these multiple peer mentor opportunities help students meet and receive advice from students further along in their academic programs, and provide mentoring programs that address somewhat different needs, there is a point at which students become over-mentored. This is a situation that needs to be addressed for year two. 


\section{Engagement of PTG Students with the Honors College Students}

To build their connection to the Honors College, first-year PTG students are required to live in the Honors residence hall, providing them with access to all living community events and programs available in the Honors hall. Students are also required to attend two Honors College events each semester and must document their attendance and reflect on the experience after each event. Further, the students interact with Honors staff during monthly meetings, during which the staff presents on available Honors College resources. Two Honors College staff meet regularly with PTG students one-on-one. As a result of this close contact, many of these students utilize the study rooms within the Honors College, greatly increasing their opportunity to engage with other Honors College staff informally, who can in turn provide additional resources that may aid the PTG scholars. This access and connection to the Honors College helps demystify the Honors College and experience the supportive community of scholars.

Although PTG students are not eligible for the $\mathrm{HC}$ when they begin their academic career at the university, they interact with $\mathrm{HC}$ students on a daily basis, particularly in the Honors residence hall and its programming. Although no formal surveys have been conducted yet to scientifically ascertain the benefits or challenges of blending PTG students with HC students, there have been observations and conversations surrounding this topic. Through these conversations, there seems to be no conflict or issues between PTG students and honors students, and the PTG students do have a feeling of belonging. There were isolated incidents involving a handful of residents displaying entitlement and elitist attitudes that caused issues between them and other residents, including other Honors as well as the non-Honors students. This situation is being addressed directly with the students this year and the next cohort will have training and programming up front to proactively address the problem.

\section{Program Assessment Plan}

To assess program effectiveness, the PTG team worked with a University of Arkansas associate professor of Education Statistics and Research Methods, Dr. Wen-Juo Lo, to develop and evaluate two surveys: a student survey to assess the performance of the students in the program and faculty mentor survey to assess their effectiveness.

\section{Student Survey}

Insights regarding the impact of the PTG program will be inferred by comparing the academic performance of PTG students with non-PTG students from the same academic disciplines and demographic cohorts across the duration of their career at University of Arkansas.

In general, eleven subscales were developed or adapted from some existing questionnaires. For pre-entry college's attitude measures, two subscales (i.e., initial perceived social support and precollege schooling) will be surveyed only in the first semester. However, for college related experiences, the data will be collected by two subscales (i.e., academic/social integration and institutional experiences) in the second semester. The rest of seven subscales will serve as the core items and will be surveyed each spring and fall semester for four years. They are: academic 
self-efficacy, career self-efficacy, self-regulation, perceived social support and financial support attitudes, goal commitment, institutional commitment, and desire to finish college.

\subsection{Pre-college Attributes}

The Initial Perceived Social Support scale (Likert-type scale, 5=Strongly agree, 1=Strongly disagree) [60] assesses the student's perception of the availability of social networks that support students in college.

The Pre-College Schooling scale asked about students' various activities while they were in high school and will only be administrated to first-year students. It included 8 items divided in to three parts: working, socializing, and academic preparations, measured on a 5-point Likert-type scale to indicate how frequently they did those activities during a regular week $(5=$ Always; $4=$ Often; 3 = Sometimes; 2 = Rarely; 1 = Never). One item is related to work (i.e., Working for pay) and one item asks about "relaxing and socializing." The remaining six items are related to academic activities, such as "Preparing for class."

\subsection{Core Integration Construct}

The Academic Self-efficacy scale (10-item 5-point Likert-type scale, with 5=Extremely confident, $1=$ Not at all confident) measures the student's self-evaluation of their ability and chances for success in the academic environment [60].

The Career Self-efficacy scale (4-item) identifies the extent to which students have confidence about their abilities to engage in educational and occupational information gathering, goal planning, and decision-making [61]. Two items are on a 5-point Likert-type scale from $5=$ Extremely confident to $1=$ Not at all confident. One item has Yes/No responses, and one item asks about their career plans at this time with the following options: 1) I've decided on a specific career, 2) I am considering one or two career options, 3) I am considering more than two career options, and 4) I haven't really thought about career options.

The Self-regulation scale (8-item 7-point Likert-type scale, with 7=Very true of me, 1=Not at all true of me) was adopted from one of the subscales from the Motivated Strategies for Learning Questionnaire (MSLQ) and it refers to the awareness, knowledge, and control of cognition. It also includes students' ability to control their effort and attention in the face of distraction and uninteresting tasks [62]. A high score on this scale indicated the respondent often evaluates himself or herself to exercise self-regulation on tasks.

The Perceived Social Support scale (12-item 5-point Likert-type scale, with 5=Strongly agree, $1=$ Strongly disagree) measures the student's perception of parents' and friends' support of them in college [60].

The Goal Commitments scale intends to evaluate a student's persistence with and commitment to action, including general and specific goal-directed behavior, in particular, commitment to attaining the college degree; and one's appreciation of the value of college education. There were six items in this scale. Two items ask about students' confidence level of completing a bachelor 
degree within 4-6 years on a 5-point Likert scale $(5=$ Extremely confident, $1=$ Not at all confident). Another four items ask about general and specific goal-directed behavior on a 5-point Likert scale ( $5=$ Strongly agree, $1=$ Strongly disagree $)$.

The Institutional Commitment scale has two items and used a 5-point Likert type scale (5=Extremely confident, $1=$ Not at all confident).

"Student motivation to achieve in college can be seen as a noncognitive dimension of the persistence phenomenon" [63]. Therefore, student's Desire to Finish College would impact his/her persistence as well as influence his/her commitment to college. This scale included six items on a 7 -point Likert type scale $(7=$ Very true of me, $1=$ Not at all true of me). Higher scores indicated stronger motivation to persist and to commit in college.

\subsection{College Experiences}

The Institutional Experiences scale included 11 items on a 4-point Likert type scale (4 = Very often, $1=$ Never). This scale intends to measure students' involvement with faculty and peers as well as their living arrangement while they are in college.

The Integration scale intends to measure participants' academic ( 8 items) and social (3 items) integration on a 5 -point Likert type scale from $5=$ Strongly agree to $1=$ Strongly disagree .

Survey results will be coupled with each student's academic information (e.g., ACT/SAT scores, university term GPA) provided by University of Arkansas Institutional Research staff. The survey, conducted online via Qualtrics Survey, was sent to all NSF designated STEM majors who started their first-year program in Summer of Fall 2018. These data are expected to be used as a baseline from which all future survey data can be compared.

In the coming weeks from time of this manuscript writing, the survey process will resume in two parts. First, the second iteration of the student survey will be sent to those who participated in the fall. Institutional Research Staff will verify each student's major to ensure only those who continue in NSF defined STEM majors remain as part of the survey sample. Based on results gleaned from the Fall Survey, the questionnaire may be revised with Institutional Review Board (IRB) approval before the next release. The survey is expected to be launched in April 2019.

\section{Faculty Mentor Survey}

A new survey will be developed to assess the effectiveness of the faculty research mentor program. This survey will address four program components: 1) the effectiveness of the three-session mentorship training program, using questions focusing on the length and timing of the training, the clarity and usefulness of content, and the interaction with the trainer and other faculty mentors during the sessions; 2) the engagement of the students in subsequent research mentoring activities throughout the semester, with questions focusing on the number, timing, and content of available activities, student participation in activities, and students' assessment of value of the activities; 3 ) the effectiveness of the chosen activities in meeting the research mentors' goals for that activity; and 4) the mentor's overall satisfaction with the chosen activities, student engagement, and other 
factors; it will also seek the mentors' input for possible program improvements. Unlike the quantitative student survey, responses will be highly qualitative. This survey is slated for a launch, after university IRB approval, in early-April.

\section{Results}

At this time, only the student survey has been disseminated. Thus, this section only summarizes results from the student survey.

The primary goal in PTG Year 1 was recruiting and initiating the first cohort of students into the project. Year 1 is a baseline year; the student survey and other data will be compared to these results in future years. There are not yet results that allow us to assess the effectiveness of the program on student achievement.

The first PTG cohort included 14 students. Twelve of the 14 students completed the initial survey, including $5(42 \%)$ females and $8(67 \%)$ from underrepresented minority populations. Nine $(75 \%)$ were engineering students, and one each from biological sciences, physics and chemistry. The survey was administered between late August and October 2018. All results are based on a 5-point Likert scale unless noted again below.

The average perceptions in academic self-efficacy for PTG students were between "very confident" and "moderately confident" $(M=3.69, S D=.64)$.

The average perceptions in career self-efficacy for PTG students were between "extremely confident" and "very confident" in average. This is an expected outcome, because eligible PTG students must declare a STEM major $(M=4.21, S D=.69)$.

The overall perceptions in self-regulation on 7-point Likert scale for PTG students were above average $(M=5.88, S D=.64)$.

PTG students initial social support from their family and/or friends $(M=4.79, S D=.28)$.

PTG students reported high perceived social support from their family and/or friends $(M=4.35$, $S D=.72)$.

Relative to financial support attitudes, two out of twelve PTG students said that they did not have enough financial support while attending University of Arkansas. When asked how concerned they were about financing their college education, 58\% of PTG students indicated that they are moderately to extremely concerned about financing their college education.

The Pre-College Schooling scale found:

- Academic activities: Results indicated PTG "often/sometimes" spent their time on academic related activities while they were in high school (M-3.34, range in average from 2.50-3.83).

- Working: Approximately 42\% of PTG students indicated they were "always/often" working for pay while they were in high school.

- Relaxing and socializing: Approximately 50\% of PTG students reported they "always/often" had relaxing and/or socializing activities while they were in high school. 
Nine (75\%) of PTG students reported they are extremely confident to not only complete a bachelor's degree but also finish within 4-6 years. In goal-directed behavior, the average score was 4.02, which indicated that PTG students in general agree with the value of college education.

Approximately 58\% of PTG students reported they are "extremely confident" that they will graduate from the University of Arkansas, and that they made the right decision to attend the University of Arkansas.

Average student motivation score was 4.58 which indicated PTG students' motivation is moderate in Year 1.

\section{Lessons Learned}

Overall, the program has seen early success, particularly for a program that started in January outside of the normal recruitment cycle and had many moving parts to put into motion.

Informal surveys of interview weekend participants and their families suggest that families were very satisfied with their experience. Families had access to university administrators, faculty, staff and students, who answered all questions and provided clear and comprehensive information about academic programs. PTG candidates had the opportunity to experience first-year student life by staying in the residence halls and interacting with college students. Most importantly, at the luncheon on Saturday, PTG candidates stated that they found the interview process to be very positive and recognized that those involved were dedicated to student success. Every candidate left campus stating that they hoped to be among the incoming PTG scholars.

The bridge program allowed the students to get comfortable with the campus, making the academic and cultural adjustment before they began fall semester classes. The one credit hour "research lite" course was highly popular among most of the students. Much of the success of that class can be attributed to the dynamic personality and teaching ability of the professor. Importantly, the students were eased into research activities, making them more comfortable with the research process. They learned to engage in teams, which will be very useful to those who will move into a research lab. As stated above, most students stated feeling either 'more excited' or 'less fearful' about engaging in research after the course than they had initially reported.

There have been some challenges, some of which have been discussed earlier. While diversity was achieved by recruiting students from underrepresented areas of the state, the combination of ethnic/gender diversity was more limited, although the percent of female candidates was still higher than for the University of Arkansas' College of Engineering. Further, the definition of rural used here was fairly narrow, omitting heavily rural areas of regions with larger towns and cities nearby. Efforts are being made (with the help of other offices on campus) to better identify the rural fringe areas in otherwise populous counties to ensure qualified students from those areas can be considered for the second cohort of PTG scholars.

The PTG program takes an aggressive approach to engage students in a meaningful undergraduate experience, drawing from a wide variety of faculty, staff, and students to help ensure program 
success. However, the team may have set unrealistic programming goals for both PTG students and faculty. For example, students were expected to plug into existing research programming in the departments (as identified by the research mentors) to minimize the need for the faculty to develop a research program for the student and putting too much burden on the faculty. However, because of conflicts in a student's class or work schedule, few students have been able to take advantage of these opportunities. Some have expressed feelings of guilt and regret for not being able to participate, feeling that they are letting their mentor down. The research mentoring programming will need to be revised in future semesters to better ensure both faculty and student participation.

Over-programming the students is of great concern and will be addressed for the next year's iteration of PTG.

\section{Summary}

The Path to Graduation program is designed to increase the number of STEM graduates by recruiting students from populations that have traditionally been overlooked - rural students with mid-range ACT/SAT scores. The program seeks to better understand the challenges faced by these rural students. PTG helps to minimize these barriers to success, providing these students with the opportunities and resources to help them perform at their full capability.

In its first year, the program has successfully established its PTG initiatives and has launched its first cohort of highly motivated students. Although it is early in the evaluation process and baseline data are still being acquired, early evidence suggests that academic and co-curricular components are helping students meet their academic goals. Faculty mentors are finding the mentor training useful. But as with many new programs, challenges arise and not everything works as planned. Certain aspects of PTG are now being re-envisioned, such as addressing the logistics of research clusters and the over-programming of student time.

During spring of 2019, additional evaluation measures will be implemented to further measure the impact of PTG components on student development. PTG student survey results will be compared with responses from a cohort of non-PTG students. Additional surveys are being developed to determine the effectiveness and satisfaction of the program components. The conference presentation will be updated to include additional data available at that time.

This material is based upon work supported by the National Science Foundation under Grant No. 1742496. Any opinions, findings, and conclusions or recommendations expressed in this material are those of the author(s) and do not necessarily reflect the views of the National Science Foundation. 


\section{References}

[1] Arkansas Department of Education, ADE Data Center, 2018. http://arkansased.gov

[2] University of Arkansas Division of Agriculture Research and Extension, "Rural Profile of Arkansas 2015: Social and Economic Trends Affecting Rural Arkansas," University of Arkansas Cooperative Extension Service Printing Services, United States Department of Agriculture, University of Arkansas, and County Governments Cooperating, 2015. www.uaex.edu/publications/pdf/MP-531.pdf

[3] W. Willingham, C. Lewis, R. Morgan, and L. Ramist, "Predicting college grades: an analysis of institutional trends over two decades," Princeton NJ: Educational Testing Service, 1990.

[4] L. Ramist, C. Lewis, and L. McCamley-Jenkins, "Student group differences in predicting college grades: sex, language and ethnic groups," New York: College Entrance Examination Board, 1994.

[5] R. Elliott, A. Stenta, R. Adair, M. Matier, and J. Scott, "Non-Asian minority students in the science pipeline at highly selective institutions," Report to the National Science Foundation, Washington, DC: National Science Foundation, 1995.

[6] N. Ware, and V. Lee, "Sex differences in choice of college science majors," Am Ed Res J, 25(4):593-614, 1988.

[7] S. Maple, F. Stage, "Influences on the choice of math/science major by gender and ethnicity," Am Ed Res J, 28(1):37-60, 1991.

[8] A. Bandura, "The explanatory and predictive scope of self-efficacy theory," J Clin and Soc Psyc, 4(3):359-373, 1986.

[9] D. Schunk, "Modeling and attributional effects on children's achievement: A self-efficacy analysis," J Ed Psych, 73(1):93-105, 1981.

[10] M. Chemers, L. Hu, and B. Garcia, "Academic self-efficacy and first-year college student performance and adjustment," J Ed Psych, 93(1):55-64, 2001.

[11] T. Bouffard-Bouchard, "Influence of self-efficacy on performance in a cognitive task," $J$ Soc Psyc, 130(3):353-363, 1990.

[12] D. Cervone, P. Peaker, "Anchoring, efficacy, and action: The influence of judgmental heuristics on self-efficacy judgments and behavior," J Personality and Soc Psych, 50(3):492-501, 1986.

[13] R. Marra, K. Rodgers, D. Shen, and B. Bogue B, "Women engineering students and selfefficacy: a multi-year, multi-institution study of women engineering student selfefficacy," J of Eng Edu, 98(1):27-38, 2009.

[14] E. Seymour, N. Hewitt, "Talking about Leaving: Factors Contributing to High Attrition Rates among Science, Mathematics \& Engineering Undergraduate Majors," Final Report to the Alfred P. Sloan Foundation, Ethnography and Assessment Research, Bureau of Sociological Research. University of Colorado. Boulder, CO, 1994.

[15] T. Murdock, "It isn’t just money: The effects of financial aid on student persistence," Review of Higher Education, 11(1):75-101, 1987.

[16] E. St. John, R. Kirshstein, and J. Noell, "The effects of students aid on persistence: A sequential analysis," Rev Higher Ed, 14(3):383-406, 1991.

[17] C. Lee, "Achieving diversity: Issues in the recruitment and retention of underrepresented racial/ethnic students in higher education: A review of the literature," Alexandria, VA: National Association of College Admission Counselors, 1991. 
[18] T. Thomason, and H. Thurber, "Strategies for the recruitment and retention of Native American students: Executive summary," Educational Document Reproduction Service No: ED435514, 1999.

[19] G. Stewart, R. Russell, and D. Wright, "The comprehensive role of student affairs in African American student retention," J Coll Admission, 154:6-11,1997, 1997.

[20] American Council on Education, "Increasing the Success of Minority Students in Science and Technology," Washington, DC, ACE, 2005.

[21] National Center for Education Statistics (NCES), "Entry and Persistence of Women and Minorities in College Science and Engineering Education (NCES 2000601)," Washington, DC: U.S. Department of Education, 2000.

[22] E. Pascarella, P. Terenzini, How college affects students, San Francisco, CA: JosseyBass Publishers, 1991.

[23] E. St. John, “The impact of student financial aid: A review of recent research," Journal of Student Financial Aid, 21(1):18-32, 1991.

[24] E. St. John, R. Kirshstein, and J. Noell, "The effects of students aid on persistence: A sequential analysis," Rev Higher Ed, 14(3):383-406, 1991.

[25] W. Habley, R. McClanahan, "What Works in Student Retention - Four-Year Public Institutions," ACT, Inc, 2004.

[26] R. Fenske, J. Porter, and C. DuBrock, "Tracking financial aid and persistence of women, minority, and needy students in science, engineering, and mathematics," Res Higher Ed, 41(1):67-94, 2000.

[27] F. Hrabowski III, et al., Overcoming the Odds: Raising Academically Successful African American Young Women, Oxford Press, 2002.

[28] A. Zeldin, and F. Pajares, "Against the odds: self-efficacy beliefs of women in mathematical, scientific, and technological careers," Am Ed Res Assoc, 37(1):215-246, 2000.

[29] R. Richardson, "If Minority Students Are to Succeed in Higher Education, Every Rung of the Ladder Must Be in Place," Chron High Educ, 35(18):A48, 1989.

[30] P. Green, The Policies and Politics of Retention and Access of African American Students in Public White Institutions. Retaining African Americans in Higher Education: Challenging Paradigms for Retaining Students, Faculty, and Administrators, ed. Lee Jones, Stylus Publishing, LLC. Sterling, Virginia. 45-57, 2001.

[31] M. Estrada, A. Woodcock, P. Hernandez, and P. Schultz, "Toward a model of social influence that explains minority student integration into the scientific community," $J E d$ Psych, 103:206-222, 2011.

[32] K. Maton, M. Sto Domingo, K. Stolle-McAllister, J. Zimmerman, and F. Hrabowsk III, "Enhancing the number of African-Americans who pursue STEM PhDs: Meyerhoff scholarship program outcomes, processes, and individual predictors, "J Women Minor Sci Eng, 15:15-37, 2009.

[33] C. Myers, and D. Pavel, "Underrepresented students in STEM: The transition from undergraduate to graduate programs," J Divers High Ed, 4:90-105, 2011.

[34] M. Pender, D. Marcotte, M. Sto Domingo, and K. Maton, "The STEM pipeline: The role of summer research experience in minority students' Ph.D. aspirations," Educ. Policy Anal Arch, 18:1-36, 2010. 
[35] P. Schultz, P. Hernandez, A. Woodcock, M. Estrada, R. Chance, M. Aguilar, R. Serpe, "Patching the pipeline: Reducing educational disparities in the sciences through minority training programs," Educ Eval Pol Anal, 33:95-114, 2011.

[36] F. Carter, M. Mandell, and K. Maton, “The influence of on-campus, academic year undergraduate research on STEM Ph. D. outcomes: Evidence from the Meyerhoff scholarship program," Educ Eval Pol Anal, 31:441-462, 2009.

[36] J. Harsh, A. Maltese, R. Tai, "Undergraduate research experiences from a longitudinal perspective," J Coll Sci Teach, 41:84-91, 2011.

[38] C. Kardash, "Evaluation of undergraduate research experience: Perceptions of undergraduate interns and their faculty mentors," J Ed Psych, 92:191-201, 2000.

[39] D. Lopatto, "Undergraduate research experiences support science career decisions and active learning," CBE Life Sciences Education, 6:297-306, 2007.

[40] P. Schultz, P. Hernandez, A. Woodcock, M. Estrada, R. Chance, M. Aguilar, and R. Serpe, "Patching the pipeline: Reducing educational disparities in the sciences through minority training programs," Educ Eval Pol Anal, 33:95-114, 2011.

[41] A. Zydney, J. Bennett, A. Shahid, and K. Bauer, "Impact of undergraduate research experience in engineering," J Eng Educ, 91:151-157, 2002.

[42] S. Elkins, J. Braxton, and G. James, “Tinto's Separation Stage and its Influence on First Semester College Student Persistence," Res High Educ, 41(2):251-267, 2000.

[43] R. Marra, K. Rodgers, D. Shen, and B. Bogue, "Leaving Engineering: A Multi-year single institution study," J Eng Educ, 101(1):6-27, 2012.

[44] J. Stoecker, E. Pascarella, and L. Wolfe, "Persistence in higher education: A 9- year test of a theoretical model," J Coll Student Dev, 29(3):196-209, 1988.

[45] M. Nettles, ed., Toward Black Undergraduate Student Equality in American Higher Education, New York, NY: Greenwood Press, 1988.

[46] Treisman U. 1992. "Studying students studying calculus: A look at the lives of minority mathematics students in college," Coll Math J, 23(5):362-372.

[47] S. Cole, and E. Barber, Increasing Faculty Diversity: The Occupational Choices of HighAchieving Minority Students, Cambridge, MA: Harvard University Press, 2003.

[48] E. Seymour, and N. Hewitt, Talking about Leaving, Boulder, CO: Westview Press, 1997.

[49] S. Walden, and C. Foor, "What's to keep you from dropping out? Student immigration into and within engineering," J of Eng Edu, 97(2):191-205, 2008.

[50] B. Nagada, S. Gregerman, J. Jonides, W. vonHippel, and J. Lerner, "Undergraduate studentfaculty research partnerships affect student retention," Rev High Ed, 22:55-72, 1998.

[51] J. Ishiyama, "Participation in Undergraduate Research and the Development of Political Science Students," Proceedings of the Annual Meeting of the American Political Science Association, Boston, MA, 2002.

[52] N. Peppas, "Student Preparation for Graduate School through Undergraduate Research," Chem Eng Educ, 15(3): 135-137, 1981.

[53] R. Highsmith, R. Denes, and M. Pierre, "Mentoring Matters," NACME Research Letter, 8(1), New York: National Action Council for Minorities in Engineering.

[54] C. Gattis, and B. Hill, "A Successful Peer Mentoring Program," Proceedings of the 114th Annual ASEE Conference \& Exposition, 2007.

[55] V. Tinto, A. Love, and P. Russo, "Building Learning Communities for New College Students: A Summary of Research Findings of the Collaborative Learning Project," 
National Center on Postsecondary Teaching, Learning an Assessment, University Park, PA, 1993.

[56] N. Shapiro, and J. Levine, Creating Learning Communities: A Practical Guide to Winning Support, Organizing for Change, and Implementing Programs, John Wiley and Sons, San Francisco, CA. 171-187, 1999.

[57] CMS.gov, "DME_Rural Zip and Formats," Centers for Medicare \& Medicaid Services, 2016. https://www.cms.gov/Medicare/Medicare-Fee-for-ServicePayment/DMEPOSFeeSched/DMEPOS-Fee-Schedule-Items/DME-Rural-Zip-andFormats.html?DLPage $=1 \& D L E n t r i e s=10 \& D L F i l t e r=z i p \& D L S o r t=2 \& D L S o r t D i r=d e s c e n$ ding, CMS, 2016.

[58] University of Arkansas Honors College website, https://honorscollege.uark.edu/about/pathprogram, 2018.

[59] S. McGuire and S. McGuire, Teach Students How to Learn. Strategies You Can Incorporate Into Any Course to Improve Student Metacognition, Study Skills and Motivation, Stylus Publishing, LLC. Sterling Virginia, 237pp, 2015.

[60] S. Robbins, K. Lauver, H. Le, D, Davis, R. Langley, and A. Carlstrom, "Do psychosocial and study skill factors predict college outcomes?," Psychological Bulletin, 130(2), 261288, 2004.

[61] K. Taylor, and N. Betz, "Applications of self-efficacy theory to the understanding and treatment of career indecision," Journal of Vocational Behavior, 22(1), 63-81, 1983.

[62] P. Pintrich, D. Smith, T. Garcia, and W. McKeachie, A manual for the use of the Motivated Strategies for Learning Questionnaire (MSLQ), Ann Arbor: National Center for Research to Improve Postsecondary Teaching and Learning, The University of Michigan, p. 23-27, 1991.

[63] D. Allen, "Desire to finish college: An empirical link between motivation and persistence," Research in Higher Education, 40(4), 461-485, 1999. 